\title{
NÍVEIS DE SILICATO DE CÁLCIO E MAGNÉSIO NA PRODUÇÃO DAS GRAMÍNEAS MARANDU E TANZÂNIA CULTIVADAS EM UM NEOSSOLO QUARTZARENICO ${ }^{1}$
}

\author{
Level of calcium and magnesium silicate in the yield of Marandu grass and Tanzania grass \\ cultivated in one Quartzsandy Neosoil
}

\author{
Caio Augustus Fortes ${ }^{2}$, José Cardoso Pinto ${ }^{3}$, Antônio Eduardo Furtini Neto 4 , \\ Augusto Ramalho de Morais ${ }^{5}$, Antônio Ricardo Evangelista ${ }^{3}$, Ronan Magalhães de Souza ${ }^{2}$
}

\begin{abstract}
RESUMO
O estudo foi conduzido em casa-de-vegetação do Departamento de Ciência do Solo da Universidade Federal de Lavras, Lavras-MG, com o objetivo de avaliar o efeito da correção da acidez do solo, por meio da aplicação de níveis de silicato de Ca e Mg, na produção das gramíneas Brachiaria brizantha cv. Marandu e Panicum maximum cv. Tanzânia-1 cultivadas em solo Neossolo Quartzarênico ortic. O delineamento experimental utilizado foi blocos ao acaso, em esquema fatorial 2 x 5 com quatro repetições, sendo duas forrageiras e cinco níveis de saturação por bases (V\% original, 40, 60, 80 e 100\%). Cada unidade experimental correspondeu a um vaso sem furos, com capacidade para $4,0 \mathrm{dm}^{3} \mathrm{de}$ solo, totalizando 40 vasos. Foram avaliadas as produções de MS por corte (PMS) e total (PTMS), a altura e o número de perfilhos. Não houve variação entre as gramíneas em altura de perfilhos. O Tanzânia foi superior ao Marandu em PMS e número de perfilhos. Houve aumento linear na PMS, PTMS e altura de perfilhos. Conclui-se que ambas as gramíneas responderam de forma positiva à elevação dos níveis de V\%, em PMS, até 54,8\%. O Tanzânia produziu mais MS em relação ao Marandu.
\end{abstract}

Termos para idexação: Brachiaria brizantha, Escória de siderurgia, Panicum maximum, saturação por bases.

\section{ABSTRACT}

This study was conducted in a greenhouse of the Soil Science Department at Universidade Federal de Lavras, Lavras-MG, with the purpose of evaluating the effect of the soil correction acidity, by the application of $\mathrm{Ca}$ and $\mathrm{Mg}$ silicate levels, in the production of grasses Brachiaria brizantha cv. Marandu and Panicum maximum cv. Tanzânia-1 cultivated in Quartzsandy Neosoil ortic. The experimental design was a randomized complete block, in 2 × 5 factorial scheme with four replicates, being two forages and five levels of base saturation (BS\%); (original BS, 40, 60, 80 and 100\%). Each experimental unit corresponded to a pot with a capacity of $4.0 \mathrm{dm}^{3}$ of soil, totalizing 40 pots. The dry matter yield (DMY) for cut and total (TDMY), height and number of tillers were evaluated. There were no variations among the grasses in tiller height. Tanzania grass was superior to Marandu grass in DMY and tiller number. There were linear increases in DMY, TDMY and tiller height as the BS\% levels increased. It follows that both grasses responded positively to the rise of BS\% in DMY until 54.8\%. Tanzania grass produced more DM in relation to Marandu grass.

Index terms: Brachiaria brizantha, Slag, Panicum maximum, Base saturation.

(Recebido em 28 de abril de 2006 e aprovado em 11 de outubro de 2006)

\section{INTRODUÇÃO}

A adoção das práticas de calagem e adubação em pastagens pelos empresários da pecuária brasileira vem crescendo em anos recentes, particularmente naquelas propriedades onde se tem optado pela intensificação do sistema de produção.
As gramíneas forrageiras pertencentes aos gêneros Panicum e Brachiaria destacam-se principalmente por serem agressivas e possuírem elevada capacidade de produção de matéria seca (MS). Esses argumentos freqüentemente são utilizados como justificativas para a não adoção das práticas de calagem e adubação. Todavia, Aguiar (1998) afirma que o conceito de que as plantas

\footnotetext{
${ }^{1}$ Parte da Dissertação de Mestrado do primeiro autor para obtenção do título de Mestre em Zootecnia.

2Engenheiro Agrônomo, Mestre, Doutorando em Zootecnia, Forragicultura e Pastagens - Departamento de Zootecnia/DZO - Universidade Federal de Lavras/UFLA - Cx. P. 3037 - 37200-000 - Lavras, MG - caioufla@yahoo.com.br, ronan@ufla.br

${ }^{3}$ Engenheiro Agrônomo, Doutor em Zootecnia, Forragicultura e Pastagens, Professor - Departamento de Zootecnia/DZO - Universidade Federal de Lavras/UFLA - Cx. P. 3037 - 37200-000 - Lavras, MG - josecard@ufla.br, aricardo@ufla.br

${ }^{4}$ Engenheiro Agrônomo, Doutor em Agronomia, Solos e Nutrição de Plantas, Professor - Departamento de Ciência do Solo/DCS - Universidade Federal de Lavras/UFLA - Cx. P. 3037 - 37200-000 - Lavras, MG - afurtini@ufla.br

${ }^{5}$ Engenheiro Agrônomo, Doutor em Estatística e Exp. Agropecuária, Professor - Departamento de Ciências Exatas/DEX - Universidade Federal de Lavras/UFLA - Cx. P. 3037 - 37200-000 - Lavras, MG - armorais@ufla.br
} 
forrageiras tropicais são de baixa exigência em fertilidade do solo deve ser modificado, haja vista que a exploração em níveis elevados de produção determina a extração de quantidades de nutrientes do solo pela planta forrageira de 2,5 a 10 vezes maiores que as quantidades extraídas pelas culturas comerciais.

O calcário tem sido o material corretivo mais utilizado no Brasil. No entanto, alguns materiais alternativos, tais como as escórias de siderurgia (silicato de $\mathrm{Ca}$ e $\mathrm{Mg}$ ), vêm se revelando como opção na busca por maiores produtividades. Estas, além de serem corretivos de solo, assim como o calcário, constituem fonte de macro e micronutrientes, e silício ( $\mathrm{Si}$ ), elemento benéfico, principalmente para plantas acumuladoras deste elemento, tais como as gramíneas tropicais. Resultados experimentais pioneiros sobre o assunto provêm da literatura estrangeira, basicamente dos Estados Unidos (PRADO et al., 2001). No Brasil, são poucos os trabalhos que tratam de respostas das culturas ao uso das escórias. No entanto, o interesse por essa pesquisa no País vem crescendo significativamente, nos últimos anos.

Sanches (2003), avaliando o efeito de quatro doses de silicato de $\mathrm{Ca}\left(0,2,4\right.$ e $\left.6 \mathrm{tha}^{-1}\right)$ e quatro ofertas de forragem $(5,10,15$ e 20\%, em kg de MS por $100 \mathrm{~kg}$ de peso vivo animal por dia) nos atributos químicos do solo e na produção de MS e composição bromatológica do braquiarão, constatou incrementos positivos na composição química da parte aérea da gramínea em relação à testemunha. $\mathrm{O}$ autor observou aumento nos teores de Si no solo e na planta, refletindo no aumento da produção de MS.

Este trabalho teve por objetivo avaliar, em casa-devegetação, o efeito da correção da acidez do solo, por meio da aplicação de níveis de silicato de $\mathrm{Ca}$ e $\mathrm{Mg}$, na produção de duas gramíneas forrageiras tropicais cultivadas em um Neossolo Quartzarênico órtico.

\section{MATERIAL E MÉTODOS}

O ensaio foi conduzido em casa-de-vegetação do Departamento de Ciência do Solo (DCS) da Universidade Federal de Lavras (UFLA), Lavras, MG, nas coordenadas geográficas de $21^{\circ} 14^{\prime}$ de latitude sul, $45^{\circ} 00^{\prime}$ de longitude oeste de Greenwich e $918 \mathrm{~m}$ de altitude, no período de dezembro de 2004 a junho de 2005.

O solo utilizado foi classificado como Neossolo Quartzarênico órtico (RQo), coletado no município de Itutinga, MG, na Usina da CEMIG, na profundidade de 0-
$20 \mathrm{~cm}$, possuindo os seguintes atributos: $\mathrm{pH} \mathrm{H}_{2} \mathrm{O}=5,5 ; \mathrm{P}$ $=5,5 \mathrm{mg} \mathrm{dm}^{-3} ; \mathrm{K}^{+}=23,0 \mathrm{mg} \mathrm{dm}^{-3} ; \mathrm{Ca}^{2+}=0,7 \mathrm{cmol}_{\mathrm{c}} \mathrm{dm}^{-3}$; $\mathrm{Mg}^{2+}=0,2 \mathrm{cmol}_{\mathrm{c}} \mathrm{dm}^{-3} ; \mathrm{Al}^{3+}=0,9 \mathrm{cmol}_{\mathrm{c}} \mathrm{dm}^{-3} ; \mathrm{H}+\mathrm{Al}^{\mathrm{c}+}=2,9$ $\mathrm{cmol}_{\mathrm{c}} \mathrm{dm}^{-3} ; \mathrm{SB}=1,0 \mathrm{cmol}_{\mathrm{c}} \mathrm{dm}^{-3} ; \mathrm{t}=1,9 \mathrm{cmol}_{\mathrm{c}} \mathrm{dm}^{-3} ; \mathrm{T}=3,9$ $\mathrm{cmol} \mathrm{dm}^{-3} ; \mathrm{m}=48 \% ; \mathrm{V}=24,9 \% ; \mathrm{MO}=1,6 \mathrm{dag} \mathrm{kg}{ }^{-1} ; \mathrm{P}-\mathrm{rem}$ $=30,3 \mathrm{mg} \mathrm{L}^{-1} ; \mathrm{Si}=5,1 \mathrm{mg} \mathrm{dm}^{-3} ;$ Areia $=90 \%$; Silte $=3 \%$; Argila $=7 \%$.

O delineamento experimental utilizado foi blocos ao acaso (DBC), com os tratamentos dispostos em um esquema fatorial 2 x 5, sendo duas gramíneas [Brachiaria brizantha (Hochst ex A. Rich.) Stapf cv. Marandu e Panicum maximum Jacq. cv. Tanzânia-1] e cinco níveis de saturações por bases do solo (V\%) (V original, 40, 60, 80 e 100\%) obtidas por meio da aplicação de doses crescentes de silicato de $\mathrm{Ca}$ e $\mathrm{Mg}$, perfazendo 10 tratamentos. Foram utilizados 4 blocos, totalizando 40 unidades experimentais (vasos), sendo o vaso de plástico, sem furos, com capacidade para 4,0 $\mathrm{dm}^{3}$ de solo cada.

As doses do corretivo foram calculadas com base na análise do solo, por meio do método de elevação de V\%, descrito pela CFSEMG (1999), adaptado da seguinte maneira:

\section{NS = T(Ve-Va)/PRNT, sendo}

NS - necessidade de silicatagem (em $\mathrm{t} \mathrm{ha}^{-1}$ ) para uma profundidade de 0-20 cm; T - CTC a pH 7,0; Ve-saturação esperada; Va - saturação atual do solo; PRNT - poder relativo de neutralização total, em \%.

As características químicas do silicato de cálcio e magnésio são: $\mathbf{C a O}=43 \% ; \mathbf{M g O}=11 \% ; \mathbf{S i O}_{2}=43 \%$ e PRNT $=70 \%$.

Foram acondicionados $4,0 \mathrm{dm}^{3}$ de solo em cada vaso após a fertilização básica e aplicação das seguintes doses de silicato: $0 ; 1,68 ; 3,90 ; 6,14$ e $8,37 \mathrm{~g} \mathrm{vaso}^{-1}$, sendo essas doses correspondentes a $0 ; 0,84 ; 1,95 ; 3,07$ e 4,18 $\mathrm{t} \mathrm{ha}^{-1}$, respectivamente. A fertilização básica foi constituída de $100 \mathrm{mg} \mathrm{dm}^{-3} \mathrm{de} \mathrm{N}, 250 \mathrm{mg} \mathrm{dm}^{-3} \mathrm{de} \mathrm{P,} 100$ $\mathrm{mg} \mathrm{dm}{ }^{-3}$ de K e $41 \mathrm{mg} \mathrm{dm}^{-3}$ de S, 4,0 $\mathrm{mg} \mathrm{dm}^{-3}$ de Fe, 3,6 mg $\mathrm{dm}^{-3} \mathrm{de} \mathrm{Mn}, 1,5 \mathrm{mg} \mathrm{dm}^{-3} \mathrm{de} \mathrm{Cu}, 5,0 \mathrm{mg} \mathrm{dm}^{-3}$ de Zn, 0,8 mg $\mathrm{dm}^{-3}$ de B e $0,15 \mathrm{mg} \mathrm{dm}^{-3}$ de Mo. Fez-se a aplicação por meio de duas soluções nutritivas, nos volumes de 50 e $20 \mathrm{~mL} \mathrm{vaso}^{-1}$ para os macro e micronutrientes, respectivamente, utilizando-se os seguintes ácidos e sais puros para análise (PA): nitrato de amônio $\left(\mathrm{NH}_{4} \mathrm{NO}_{3}\right)$, ácido fosfórico $\left(\mathrm{H}_{3} \mathrm{PO}_{4}\right)$, sulfato de potássio $\left(\mathrm{K}_{2} \mathrm{SO}_{4}\right)$, fosfato monoamônico $\left(\mathrm{NH}_{4} \mathrm{H}_{2} \mathrm{PO}_{4}\right)$, sulfato ferroso 
$\left(\mathrm{FeSO}_{4} \cdot 7 \mathrm{H}_{2} \mathrm{O}\right)$, sulfato de manganês $\left(\mathrm{MnSO}_{4} \cdot 4 \mathrm{H}_{2} \mathrm{O}\right)$, sulfato de cobre $\left(\mathrm{CuSO}_{4} .5 \mathrm{H}_{2} \mathrm{O}\right)$, sulfato de zinco $\left(\mathrm{ZnSO}_{4} \cdot \mathrm{H}_{2} \mathrm{O}\right)$, ácido bórico $\left(\mathrm{H}_{3} \mathrm{BO}_{3}\right)$ e molibdato de amônio $\left[\left(\mathrm{NH}_{4}\right)_{6} \mathrm{Mo}_{7} \mathrm{O}_{24} \cdot 4 \mathrm{H}_{2} \mathrm{O}\right]$.

Os vasos permaneceram em incubação por 30 dias, com a umidade do solo mantida na capacidade de campo, por meio de pesagem diária e adição de água destilada, quando necessário. Os vasos permaneceram cobertos com jornais, a fim de diminuir as perdas de água.

Após a incubação foram retiradas amostras de solo de cada vaso para análise química (Tabela 1). Em seguida, foram semeadas 30 sementes por vaso, em profundidade média de 0,5 cm. Após duas semanas fez-se um desbaste, deixando-se quatro plantas por vaso.

Após cada corte efetuou-se uma adubação de cobertura com $\mathrm{N}$ e $\mathrm{K}$ da seguinte forma: após o primeiro corte fez-se duas aplicações de uma solução contendo 50 $\mathrm{mg} \mathrm{dm}{ }^{-3}$ de $\mathrm{N}$ e $40 \mathrm{mg} \mathrm{dm}^{-3}$ de $\mathrm{K}$, com intervalo de três semanas, utilizando-se as fontes $\left(\mathrm{NH}_{4}\right)_{2} \mathrm{SO}_{4}$ e $\mathrm{KCl}$; após o segundo corte, efetuou-se cinco aplicações de solução constituída de $30 \mathrm{mg} \mathrm{dm}^{-3}$ de $\mathrm{Ne} 25 \mathrm{mg} \mathrm{dm}^{-3}$ de $\mathrm{K}$, em intervalos de uma semana, por meio das fontes $\mathrm{NH}_{4} \mathrm{NO}_{3} \mathrm{e}$ $\mathrm{K}_{2} \mathrm{SO}_{4}$. Em cada fertilização utilizou-se $50 \mathrm{~mL}$ vaso $^{-1} \mathrm{de}$ solução estoque.

Antes de cada corte foram escolhidos, ao acaso, quatro perfilhos por vaso (um por touceira) e, com o auxílio de uma trena, mediu-se a distância entre o solo e a lígula da última folha completamente expandida. Em seguida, procedeu-se à contagem do número total de perfilhos por vaso.

Foram realizados três cortes na altura de $3 \mathrm{~cm}$ do solo, utilizando-se tesoura de poda, sendo o primeiro efetuado sete semanas após a semeadura e os seguintes com intervalos de seis semanas. Após cada corte, os materiais vegetais (parte aérea) de cada vaso foram acondicionados em sacos de papel e imediatamente pesados para a obtenção das produções de massa verde. Em seguida, foram mantidos em estufa de ventilação forçada a $65^{\circ} \mathrm{C}$, durante 72 horas, obtendo-se a massa seca.

Após a análise de variância dos dados, as médias foram submetidas ao estudo de regressão para o fator V\% e comparação pelo teste $\mathrm{F}$ para o fator espécie, utilizandose o programa computacional Sistema de Análise de Variância para Dados Balanceados (SISVAR) (FERREIRA, 1999). Para as variáveis cujas interações foram significativas, procederam-se os seus desdobramentos. As análises estatísticas foram realizadas para cada corte isoladamente e soma dos cortes no caso da PTMS. A seqüência de cortes foi realizada com o objetivo de simular ciclos de pastejo, não sendo, portanto, considerada como um fator no modelo estatístico.

Tabela 1 - Atributos químicos do Neossolo Quatzarênico órtico em função das doses de silicato de Ca e Mg após 30 dias de incubação.

\begin{tabular}{lrrrrr}
\hline \multirow{2}{*}{ Atributo } & \multicolumn{5}{c}{ Dose de silicato de Ca e Mg $\left(\mathrm{g} \mathrm{vaso}^{-1}\right)$} \\
\cline { 2 - 6 } $\mathrm{pH}$ & \multicolumn{1}{c}{0} & 1,68 & 3,90 & 6,14 & 8,36 \\
$\mathrm{P}\left(\mathrm{mg} \mathrm{dm}^{-3}\right)$ & 4,9 & 4,8 & 4,6 & 4,6 & 4,7 \\
$\mathrm{~K}^{+}\left(\mathrm{mg} \mathrm{dm}^{-3}\right)$ & 232,1 & 225,0 & 246,8 & 254,3 & 254,3 \\
$\mathrm{Ca}^{2+}\left(\mathrm{cmolc} \mathrm{dm}^{-3}\right)$ & 119 & 111 & 126 & 131 & 125 \\
$\mathrm{Mg}^{2+}\left(\mathrm{cmolc} \mathrm{dm}^{-3}\right)$ & 0,4 & 0,8 & 1,2 & 1,7 & 2,1 \\
$\mathrm{~S}\left(\mathrm{mg} \mathrm{dm}^{-3}\right)$ & 0,2 & 0,2 & 0,4 & 0,6 & 1,1 \\
$\mathrm{Si}\left(\mathrm{mg} \mathrm{dm}^{-3}\right)$ & 127,4 & 123,8 & 181,2 & 59,4 & 56,0 \\
$\mathrm{Al}^{3+}\left(\mathrm{cmolc} \mathrm{dm}^{-3}\right)$ & 4,8 & 7,4 & 7,4 & 8,0 & 9,8 \\
$\mathrm{H}+\mathrm{Al}^{3+}\left(\mathrm{cmolc} \mathrm{dm}^{-3}\right)$ & 0,6 & 0,5 & 0,4 & 0,3 & 0,2 \\
$\mathrm{SB}\left(\mathrm{cmolc} \mathrm{dm}^{-3}\right)$ & 0,4 & 3,6 & 3,2 & 3,2 & 2,9 \\
$(\mathrm{t})\left(\mathrm{cmolc} \mathrm{dm}^{-3}\right)$ & 0,9 & 1,3 & 1,9 & 2,6 & 3,5 \\
$(\mathrm{~T})\left(\mathrm{cmolc} \mathrm{dm}^{-3}\right)$ & 1,5 & 1,8 & 2,3 & 2,9 & 3,7 \\
$\mathrm{~m} \%$ & 4,9 & 4,9 & 5,1 & 5,8 & 6,4 \\
$\mathrm{~V} \%$ & 40 & 28 & 17 & 10 & 5 \\
\hline
\end{tabular}

Laboratório de Análise de Solo do DCS/UFLA, 2005. 


\section{RESULTADOS E DISCUSSÃO}

Observa-se, na Tabela 1, que houve aumento discreto da V\% do solo em função das doses de silicato de $\mathrm{Ca}$ e $\mathrm{Mg}$. No entanto, nota-se que não houve variação nos valores de $\mathrm{pH}$, fato que pode ser atribuído a um possível erro de análise, uma vez que há relação direta entre V\% e pH do solo.

As baixas saturações por bases alcançadas após o período de incubação são atribuídas à baixa reatividade do silicato, em decorrência de sua granulometria mais grosseira e sua base química, o $\mathrm{SiO}_{2}$, possuir baixa eficiência relativa, refletindo, assim, em um baixo PRNT. Nesse sentido, levando-se em conta o alto efeito residual do silicato, a incubação do solo deve ser realizada por período mais longo do que o utilizado no presente estudo.

Após o experimento, houve pequena redução das saturações por bases em relação às registradas após a incubação (na semeadura) (Tabelas 1 e 2). Esses resultados indicam que houve extração de bases pelas plantas, ao mesmo tempo em que o corretivo reagiu no decorrer do experimento.

Na PMS, observou-se efeito significativo das gramíneas no primeiro $(\mathrm{P}<0,05)$ e segundo $(\mathrm{P}<0,01)$ cortes e das saturações por bases $(\mathrm{P}<0,01)$, no segundo e terceiro cortes.

Neste estudo, o Tanzânia apresentou maior PMS em relação ao Marandu. A superioridade observada no Tanzânia no primeiro e segundo cortes foi de 18,5 e 16,1\%, respectivamente (Tabela 3 ). Essa diferença pode ser atribuída a fatores genéticos, uma vez que as gramíneas diferem entre si quanto ao potencial de PMS, que é de 8 a $10 \mathrm{t} \mathrm{ha}^{-1} \mathrm{ano}^{-1}$ na cultivar Marandu (ALCÂNTARA \& BUFARAH, 1985) e chegando a $26 \mathrm{t} \mathrm{ha}^{-1} \mathrm{ano}^{-1}$ na cultivar Tanzânia-1 (CORSI \& SANTOS, 1995).

Tabela 2 - Atributos químicos do Neossolo Quartzarênico órtico em função de gramíneas e doses de silicato de Ca e Mg, após o terceiro corte.

\begin{tabular}{|c|c|c|c|c|c|c|c|c|c|c|}
\hline \multirow{4}{*}{ Atributo } & \multicolumn{10}{|c|}{ Gramínea } \\
\hline & \multicolumn{5}{|c|}{ Marandu } & \multicolumn{5}{|c|}{ Tanzânia } \\
\hline & \multicolumn{10}{|c|}{ Dose de silicato de $\mathrm{Ca}$ e $\mathrm{Mg}\left(\mathrm{g} \mathrm{vaso}^{-1}\right)$} \\
\hline & 0 & 1,68 & 3,90 & 6,14 & 8,36 & 0 & 1,68 & 3,90 & 6,14 & 8,36 \\
\hline $\mathrm{pH}$ & 4,5 & 4,8 & 4,9 & 5,3 & 5,5 & 4,6 & 4,6 & 5,0 & 5,3 & 5,5 \\
\hline $\mathrm{P}$ & 117,1 & 124,4 & 117,1 & 120,4 & 120,4 & 120,4 & 130,8 & 117,1 & 105,1 & 123,8 \\
\hline $\mathrm{K}^{+}$ & 23,0 & 16,0 & 16,0 & 14,0 & 14,0 & 25,0 & 25,0 & 27,0 & 25,0 & 28,0 \\
\hline $\mathrm{Ca}^{2+}$ & 0,4 & 0,5 & 0,8 & 1,2 & 1,6 & 0,4 & 0,4 & 0,7 & 1,0 & 1,5 \\
\hline $\mathrm{Mg}^{2+}$ & 0,2 & 0,2 & 0,2 & 0,2 & 0,2 & 0,1 & 0,1 & 0,2 & 0,3 & 0,2 \\
\hline $\mathrm{Si}$ & 2,9 & 3,0 & 4,1 & 4,4 & 5,5 & 3,2 & 3,3 & 3,9 & 3,9 & 4,9 \\
\hline $\mathrm{Al}^{3+}$ & 1,0 & 0,9 & 0,7 & 0,5 & 0,3 & 1,3 & 1,0 & 0,7 & 0,5 & 0,3 \\
\hline $\mathrm{H}+\mathrm{Al}^{3+}$ & 3,2 & 2,6 & 2,9 & 2,3 & 2,1 & 3,2 & 3,2 & 2,9 & 2,6 & 2,3 \\
\hline SB & 0,7 & 0,7 & 1,0 & 1,4 & 1,8 & 0,6 & 0,6 & 1,0 & 1,4 & 1,8 \\
\hline$(\mathrm{t})$ & 1,7 & 1,6 & 1,7 & 1,9 & 2,1 & 1,9 & 1,6 & 1,7 & 1,9 & 2,1 \\
\hline (T) & 3,9 & 3,3 & 3,9 & 3,7 & 3,9 & 3,8 & 3,8 & 3,9 & 4,0 & 4,1 \\
\hline $\mathrm{m} \%$ & 60,0 & 55,0 & 40,0 & 26,0 & 14,0 & 70,0 & 64,0 & 42,0 & 27,0 & 14,0 \\
\hline $\mathrm{V} \%$ & 17,1 & 22,2 & 26,4 & 38,5 & 46,7 & 14,9 & 14,9 & 25,1 & 34,3 & 43,5 \\
\hline
\end{tabular}

$\mathrm{P}=\mathrm{mg} \mathrm{dm}^{-3} ; \mathrm{K}^{+}=\mathrm{mg} \mathrm{dm}^{-3} ; \mathrm{Ca}^{2+}=\mathrm{cmol}_{\mathrm{c}} \mathrm{dm}^{-3} ; \mathrm{Mg}^{2+}=\mathrm{cmol}_{\mathrm{c}} \mathrm{dm}^{-3} ; \mathrm{Si}=\mathrm{mg} \mathrm{dm}^{-3} ; \mathrm{Al}^{3+}=\mathrm{cmol}_{\mathrm{c}} \mathrm{dm}^{-3} ; \mathrm{H}+\mathrm{Al}^{3+}=\mathrm{cmol}_{\mathrm{c}} \mathrm{dm}^{-3} ; \mathrm{SB}^{2} \mathrm{cmol}_{\mathrm{c}} \mathrm{dm}^{-}$ ; $;(\mathrm{t})=\mathrm{cmol}_{\mathrm{c}} \mathrm{dm}^{-3} ;(\mathrm{T})=\mathrm{cmol}_{\mathrm{c}} \mathrm{dm}^{-3}$.

Laboratório de Análise de Solo do DCS/UFLA, 2005.

Tabela 3 - Produções de MS (PMS) das gramíneas Marandu e Tanzânia submetidas a níveis de saturação por base de um solo RQo, nos três cortes e total (PTMS).

\begin{tabular}{|c|c|c|c|c|c|}
\hline \multirow{2}{*}{ Gramínea } & \multicolumn{3}{|c|}{ PMS $\left(\right.$ g vaso $\left.^{-1}\right)$} & \multirow{2}{*}{ Média } & \multirow{2}{*}{ PTMS $\left(\right.$ g vaso $\left.^{-1}\right)$} \\
\hline & $1^{\circ}$ corte & $2^{\circ}$ corte & $3^{\circ}$ corte & & \\
\hline Marandu & $21,00 b$ & $15,47 b$ & $13,98 \mathrm{a}$ & 18,23 & $50,45 b$ \\
\hline Tanzânia & $24,88 \mathrm{a}$ & $17,96 a$ & $14,77 \mathrm{a}$ & 21,42 & $57,61 \mathrm{a}$ \\
\hline Média & 22,94 & 16,71 & 14,37 & 14,38 & 54,03 \\
\hline
\end{tabular}

Médias seguidas de mesma letra na coluna não diferem entre si, pelo teste $\mathrm{F}(\mathrm{P}>0,05)$. 
A CFSEMG (1999), $5^{\text {a }}$ aproximação, recomenda, para o estabelecimento dessas gramíneas, a elevação da saturação por bases para 45-50\% no Tanzânia e 45\% no Marandu. No Estado de São Paulo, a recomendação é de $60 \%$ para o estabelecimento e $50 \%$ para a manutenção dessas cultivares (WERNER et al., 1997, citados por LUZ et al., 2004).

Premazzi (1991), estudando níveis de saturação por bases como critério de recomendação de calagem em cinco gramíneas forrageiras tropicais, em um Latossolo VermelhoAmarelo distrófico, observou efeito dos tratamentos na produção de MS, com ajuste quadrático nas cultivares Marandu e Colonião, com produções máximas obtidas nas saturações de 43 a $47 \%$ no Marandu e de $47 \%$ no Colonião.

Por sua vez, Mitidieri (1995), testando níveis crescentes de calagem em cinco gramíneas forrageiras cultivadas em um Latossolo Vermelho-Escuro, observou que, independentemente do nível de calagem, houve maior resposta da cultivar Colonião IZ-1, que foi significativamente superior às cultivares Vencedor, Centenário e Marandu, não havendo diferenças significativas entre as produções dessas três últimas.

As PMS das gramíneas nos dois últimos cortes aumentaram linearmente em função dos níveis de saturação por bases (Figura 1). No segundo corte houve incremento de $0,10 \mathrm{~g}$ de MS para cada $1 \%$ de aumento na saturação por bases do solo, enquanto, no terceiro, esse aumento foi de $0,12 \mathrm{~g}$.

Quanto à PTMS, observou-se influência significativa $(\mathrm{P}<0,01)$ das gramíneas e dos níveis de saturação por bases. O Tanzânia apresentou PTMS 14,21\% superior ao Marandu, os quais atingiram médias de 57,61 e $50,45 \mathrm{~g} \mathrm{vaso}^{-1}$, respectivamente.
Semelhantemente ao observado na PMS, o estudo de regressão revelou ajuste linear nos valores da PTMS, estimando-se incremento de $0,33 \mathrm{~g}$ vaso $^{-1}$ para cada $1 \%$ de elevação na saturação por bases do solo (Figura 2).

$\mathrm{O}$ efeito positivo observado na PTMS pode ser atribuído, principalmente, à elevação do $\mathrm{pH}$, com conseqüente neutralização do Al trocável e do fornecimento de $\mathrm{Ca}, \mathrm{Mg}$ e Si. Apesar de, após a incubação, não ter sido observada elevação no $\mathrm{pH}$ do solo pelas doses de silicato (Tabela 1), durante a condução do experimento esse aumento ocorreu de modo progressivo, de sorte que, após o terceiro corte, foram obtidos valores de $\mathrm{pH}$ de 4,5 no tratamento controle e 5,5 na dose mais alta do corretivo (Tabela 2).

No geral, as gramíneas apresentaram maior PMS no primeiro corte, havendo redução nos cortes subsequientes. Provavelmente, essa queda está relacionada à redução das temperaturas e fotoperíodos (dados não apresentados), uma vez que o experimento foi conduzido durante o outono e início do inverno.

Vilela et al. (2005), trabalhando com níveis de silicato de Ca em capim-elefante cv. Paraíso (Pennisetum purpureum x P. glaucum), obtiveram produção de $11,75 \mathrm{t} \mathrm{ha}^{-1}$ de MS na dose de $500 \mathrm{~kg} \mathrm{ha}^{-1}$ de silicato de Ca, sendo superior em $15,19 \%$ ao tratamento controle. Os autores não observaram aumento significativo da produção de MS quando a dose do corretivo foi aumentada para $1.000 \mathrm{~kg} \mathrm{ha}^{-1}$.

Korndörfer et al. (2001) verificaram aumento de 17\% na produção de MS de $B$. decumbens após a aplicação superficial de $2 \mathrm{t} \mathrm{ha}^{-1}$ de silicato de $\mathrm{Ca}$, em experimento de campo conduzido na região do Triângulo Mineiro.

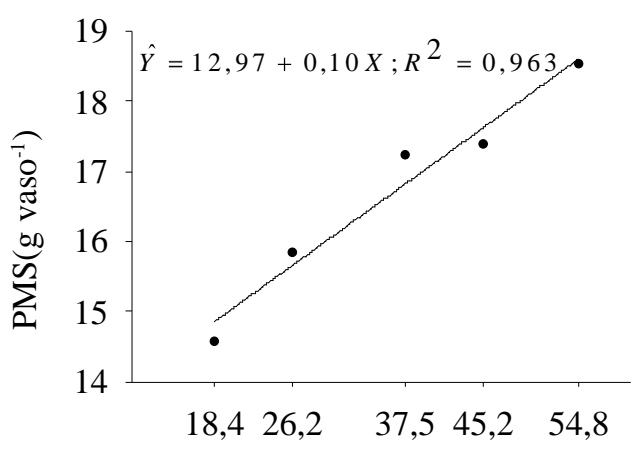

Saturação por bases do solo (V\%) b

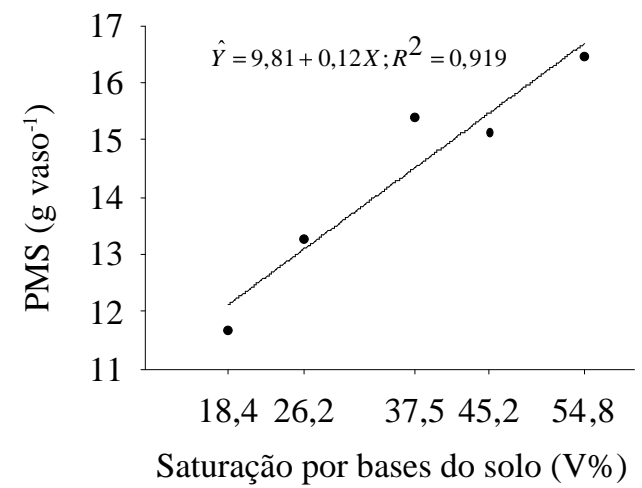

Figura 1 - Produção de MS (PMS) das gramíneas Marandu e Tanzânia em função de níveis de saturação por bases de um solo RQo no segundo (a) e terceiro (b) cortes. 


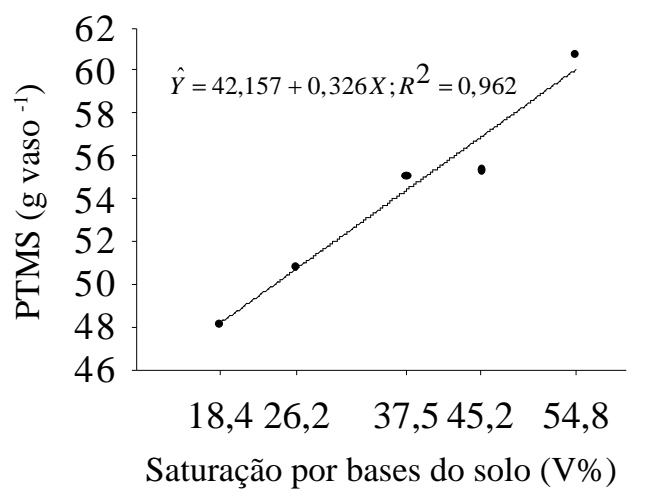

Figura 2 - Produção total de MS (PTMS) das gramíneas Marandu e Tanzânia em função de níveis de saturação por bases de um solo RQo.

Os valores das alturas de perfilhos das gramíneas foram influenciados significativamente $(\mathrm{P}<0,01)$ somente pelos níveis de saturação por bases no segundo e terceiro cortes.

No estudo de regressão verificou-se aumento linear da altura de perfilhos de ambas as forrageiras em função dos níveis de saturação por bases do solo, no segundo e terceiro cortes (Figura 3). Assim, estimou-se aumentos de $0,13 \mathrm{~cm}$ no segundo e $0,22 \mathrm{~cm}$ no terceiro corte, para cada $1 \%$ de elevação na saturação por bases. Esses resultados mostram que as gramíneas foram altamente responsivas à correção do solo com silicato de $\mathrm{Ca}$ e $\mathrm{Mg}$. A magnitude dessa resposta sugere que maiores alturas de perfilhos podem ser alcançadas em níveis mais elevados de saturação por bases, nas condições do presente estudo.

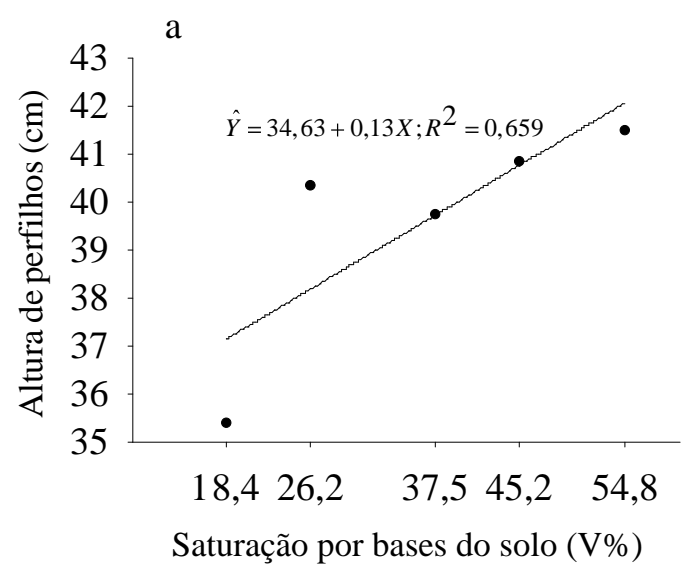

As respostas das gramíneas quanto às alturas de perfilhos encontradas nesse estudo discordam das obtidas por Mitidieri (1995), que não observou efeito de doses de calcário aplicadas em Latossolo Vermelho-Escuro nas alturas das hastes principais das cultivares Colonião, Vencedor, Centenário e Marandu. Entretanto, o autor detectou diferença entre as cultivares, tendo a Centenário apresentado menor altura do que as outras três gramíneas. Esses resultados sugerem que o efeito positivo do silicato nas alturas de perfilhos neste estudo pode estar relacionado aos efeitos benéficos do $\mathrm{Si}$.

No número de perfilhos, observou-se influência significativa $(\mathrm{P}<0,01)$ das gramíneas no primeiro e terceiro cortes e da interação gramínea $\mathrm{x}$ saturação por bases $(\mathrm{P}<0,05)$ no terceiro corte.

No primeiro corte, o número médio de perfilhos por vaso foi $84,4 \%$ superior no Tanzânia em relação ao Marandu (Tabela 4).

No terceiro corte, observou-se que houve redução linear do número de perfilhos por vaso do Tanzânia em função do aumento dos níveis de saturação por bases do solo, não havendo ajuste de equação de regressão para o Marandu (Figura 4). Observou-se, no Tanzânia, redução de 0,45 perfilhos por vaso para cada $1 \%$ de elevação na saturação por bases. No Marandu, a falta de ajuste mostrou que não houve influência da elevação dos níveis de saturação por bases do solo no perfilhamento da forrageira.

Com os aumentos observados na PMS e altura de perfilhos no terceiro corte, supõe-se que tenha ocorrido aumento no peso de perfilhos do Tanzânia. Assim, pode ter havido compensação entre peso e número de perfilhos, uma vez que essas variáveis normalmente exibem correlação inversa.

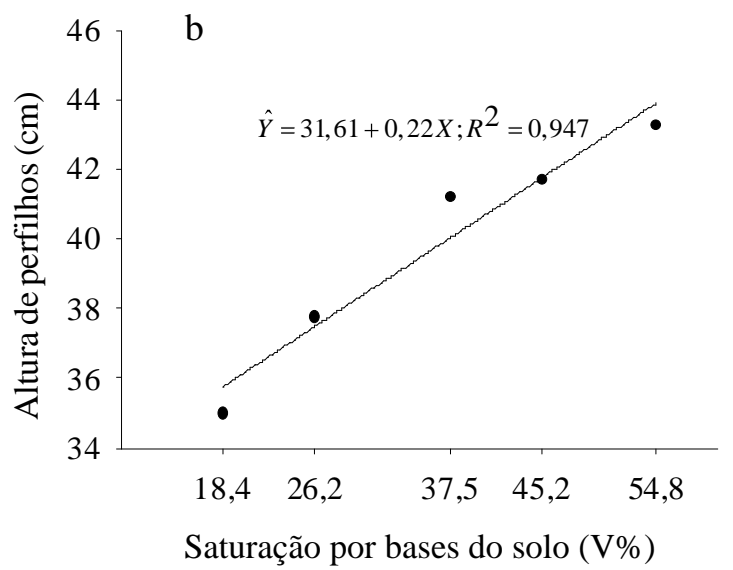

Figura 3 - Altura de perfilhos das gramíneas Marandu e Tanzânia em função de níveis de saturação por bases de um solo RQo, no segundo (a) e terceiro (b) cortes. 
Tabela 4 - Número de perfilhos por vaso das gramíneas Marandu e Tanzânia submetidas a níveis de saturação por base de um solo RQo, nos três cortes.

\begin{tabular}{llclc}
\hline \multirow{2}{*}{ Gramínea } & \multicolumn{3}{c}{ Número de perfilhos } & \multirow{2}{*}{ Média } \\
\cline { 2 - 4 } & $1^{\circ}$ corte & $2^{\circ}$ corte & $3^{\circ}$ corte & 39,26 \\
Marandu & $20,05 \mathrm{~b}$ & $39,45 \mathrm{a}$ & $58,30 \mathrm{~b}$ & 51,33 \\
Tanzânia & $37,15 \mathrm{a}$ & $41,50 \mathrm{a}$ & $75,35 \mathrm{a}$ & 45,29 \\
Média & 28,60 & 40,47 & 66,82 & \\
\hline
\end{tabular}

Médias seguidas de mesma letra na coluna não diferem entre si, pelo teste $\mathrm{F}(\mathrm{P}>0,05)$.

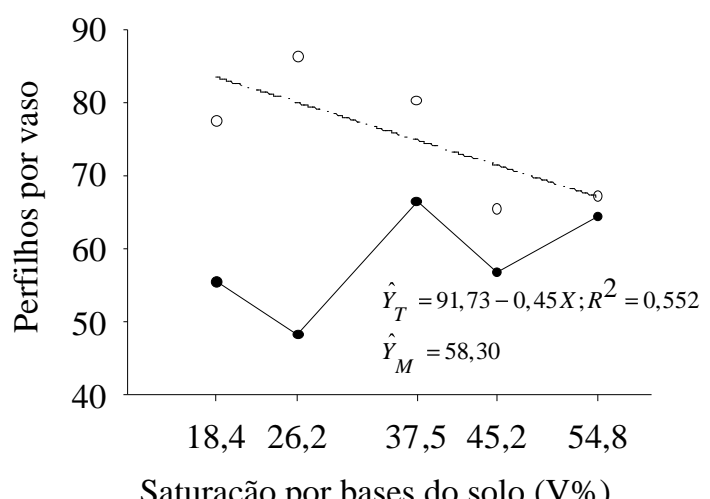

Figura 4 - Número de perfilhos das gramíneas Marandu (—•) e Tanzânia (-_o) em função de níveis de saturação por bases de um solo RQo, no terceiro corte.

Luz et al. (2000), estudando os efeitos de tipos, doses e incorporação de calcário no capim-Tobiatã $(P$. maximum cv. Tobiatã), constataram que o número e o peso médio de perfilhos apresentaram comportamento inversamente proporcional $(\mathrm{r}=-0,59)$, bem como as correlações entre produção de MS e número de perfilhos $(\mathrm{r}=-0,52)$.

\section{CONCLUSÕES}

As gramíneas Marandu e Tanzânia-1 responderam de forma positiva à elevação dos níveis de saturação por bases do solo até $54,8 \%$.

Os incrementos de MS em função dos níveis de silicato estiveram associados ao aumento das alturas de perfilhos.

\section{REFERÊNCIAS BIBLIOGRÁFICAS}

AGUIAR, A. de P. A. Manejo da fertilidade do solo sob pastagem, calagem e adubação. Guaíba: Agropecuária, 1998. $120 \mathrm{p}$.
ALCÂNTARA, P. B.; BUFARAH, G. Plantas forrageiras: gramíneas e leguminosas. São Paulo: Nobel, 1985. 162 p.

COMISSÃO DE FERTILIDADE DO SOLO DO ESTADO DE MINAS GERAIS. Recomendações para o uso de corretivos e fertilizantes em Minas Gerais: $5^{\mathrm{a}}$ aproximação. Viçosa, 1999. 359 p.

CORSI, M.; SANTOS, P. M. Potencial de produção do Panicum maximum. In: SIMPÓSIO SOBRE MANEJO DA PASTAGEM, 12., 1995, Piracicaba, SP. Anais... Piracicaba: FEALQ, 1995. p. 275-303.

FERREIRA, D. F. SISVAR - Sistema de análise de variância para dados balanceados. Lavras: UFLA/DEX, 1999.

KORNDÖRFER, C. M.; KORNDÖRFER, G. H.; PEÇANHA, M. R.; CORREA, G. F.; JUNQUEIRA NETO, A. A. Correção da acidez do solo com silicato de cálcio e o papel do silício na recuperação de pastagem de Brachiaria decumbens. In: CONGRESSO BRASILEIRO DE CIÊNCIA DO SOLO, 28., 2001, Londrina. Anais... Londrina: Sociedade Brasileira de Ciência do Solo, 2001. p. $144-144$.

LUZ, P. H. de C.; HERLING, V. R.; BRAGA, G. J.; OLIVEIRA, P. P. A. Uso da calagem na recuperação e manutenção da produtividade das pastagens. In: SIMPÓSIO SOBRE MANEJO DA PASTAGEM, 21., 2004, Piracicaba, SP. Anais... Piracicaba: FEALQ, 2004. p. 63-100.

LUZ, P. H. de C.; HERLING, V. R.; BRAGA, G. J.; VITTI, G. C.; LIMA, C. G. de. Efeitos de tipos, doses e incorporação de calcário sobre características agronômicas e fisiológicas do capim-Tobiatã (Panicum maximum Jacq.). Revista Brasileira de Zootecnia, Viçosa, v. 29, n. 4, p. 964-970, 2000. 
MITIDIERI, F. J. Resposta de cinco gramíneas forrageiras a níveis de calcário em um Latossolo Vermelho-Escuro. 1995. 137 f. Dissertação (Mestrado em Ciência Animal e Pastagens) - Escola Superior de Agricultura "Luiz de Queiroz”, Universidade de São Paulo, Piracicaba, 1995.

PRADO, R. M.; FERNANDES, F. M.; NATALE, W. Uso de escória de siderurgia no Brasil: estudos na cultura da cana-de-açúcar. Jaboticabal: Funep, 2001. 67 p.

PREMAZZI, L. M. Saturação por bases como critério para recomendação de calagem em cinco forrageiras tropicais. 1991. 215 f. Dissertação (Mestrado em Nutrição Animal e Pastagens) - Escola Superior de Agricultura "Luiz de Queiroz”, Universidade de São Paulo, Piracicaba, 1991.
SANCHES, A. B. Efeitos do silicato e calcário nos atributos químicos do solo e planta, produção e qualidade em capim-Braquiarão [Brachiaria brizantha (Hochst ex A. Rich.) Stapf cv. Marandu] sob intensidades de pastejo. 2003. 122 f. Dissertação (Mestrado em Zootecnia) - Faculdade de Zootecnia e Engenharia de Alimentos da USP, Pirassununga, 2003.

VILELA, H.; VILELA, D.; BARBOSA, F. A.; MELO, A. A.; BENEDETTI, E. Efeito de níveis de silicato sobre a produção de forragem, composição bromatológica e digestibilidade de gramínea tropical. Disponível em: <http://www.agronomia.com.br/conteudo/artigos/ artigos_silicato_ca_mg.htm>. Acesso em: 20 dez. 2005. 